\title{
ANALISIS HUBUNGAN ANTARA KEPUASAN PELANGGAN DAN LOYALITAS PELANGGAN TERHADAP KEINGINAN PEMBELIAN ULANG, STUDI KASUS DI UNIVERSITAS BUNDA MULIA
}

\author{
Y.B Andre \\ Email : silabalaba@yahoo.com
}

\section{Penulis}

Y.B. Andre adalah staf pengajar tetap pada Jurusan Manajemen Universitas Krida Wacana, Jakarta.

\section{Abstract}

The purpose of this paper is to obtain a better understanding of the relationship among customer satisfaction and customer loyalty to repurchase intention. One of the methods used in this paper is by surveying students (as customers) from 12 departments in Bunda Mulia University (UBM). The students have to fill in the questionnaires related to customer satisfaction, customer loyalty and repurchase intention concepts. A total of 232 students filled in the questionnaires. The results support the conceptual model in demonstrating a strong relationship among customer satisfaction and customer loyalty to repurchase intention. One of the findings shows that the dimension of satisfaction does not directly support repurchase intention. This research adds to the body of knowledge related to customer satisfaction management.

\section{Key Words}

Consumer Satisfaction, Repurchase Intention

\section{PENDAHULUAN}

Pendidikan tinggi sebagai institusi ilmiah mencerminkan unsur-unsur dalam kelembagaan dan berbagai kegiatan fungsionalnya untuk menghasilkan 
keluaran yang berkualitas. Perguruan tinggi di Indonesia dapat diklasifikasikan sebagai: akademi, institut, politeknik, sekolah tinggi, dan universitas. Perguruan tinggi dapat dilihat dalam wujud sistem sarana dan prasarana yang segera dapat dilihat oleh semua orang, sehingga yang diutamakan dalam suatu perguruan tinggi selain tenaga pengajar yang berkualitas juga tenaga non akademik, ruangkuliah, perpustakaan, sarana kegiatan mahasiswa, dan lain-lain.

Globalisasi telah memaksa setiap individu dan organisasi di manapun untuk melakukan transformasi diri. Hal ini berarti setiap perguruan tinggi perlu menata diri untuk mempersiapkan masa depan. Masyarakat sebagai pengguna jasa perguruan tinggi menuntut kualitas pendidikan yang tinggi. Ini merupakan tantangan yang harus dihadapi sebagai kenyataan yang harus dihadapi dengan realistis.

Mutu pelayanan suatu lembaga pendidikan merupakan produk akhir dari interaksi dan ketergantungan yang saling terkait antar berbagai unsur/aspek lembaga pendidikan tersebut sebagai suatu sistem. Dalam rangka meningkatkan mutu pelayanan, perlu dilakukan usaha yang terus menerus secara berlanjut untuk perbaikan pelayanan yang diberikan kepada para mahasiswasiswa. Untuk melakukan perbaikan-perbaikan tersebut, manajemen lembaga pendidikan perlu melakukan survai kepuasan para siswa.

Dengan adanya beragam nama perguruan tinggi yang ditawarkan kepada calon mahasiswa (sebagai konsumen), para konsumen kini memiliki kebebasan memilih nama perguruan tinggi yang disukainya. Konsumen akan berusaha memilih perguruan tinggi yang mampu memenuhi atau memuaskan harapannya. Ada beberapa alasan kenapa seorang konsumen memilih suatu nama perguruan tinggi seperti: bagaimana interaksi antara pengelola perguruan tinggi dengan para mahasiswa sebagai pengguna jasa perguruan tinggi, bagaimana lingkungan dari lembaga pendidikan tinggi dapat mempengaruhi kesan para mahasiswa sebagai pengguna jasa perguruan tinggi, dan bagaimanakah hasil yang diberikan pengelola pendidikan tinggi tersebut dapat mempengaruhi penilaian kualitas jasa para mahasiswa sebagai pengguna jasa. 
Para mahasiswa yang puas menjadi loyal terhadap perguruan yang bersangkutan, selanjutnya mahasiswa tersebut akan merekomendasikan kepada para calon mahasiswa terhadap suatu nama perguruan tinggi tertentu jika fasilitas yang ditawarkan oleh perguruan tinggi tersebut lebih besar dibandingkan dengan nama-nama perguruan tinggi lainnya. Situasi persaingan yang ketat ini menyebabkan banyak perguruan tinggi mengalami kesulitan untuk meningkatkan jumlah mahasiswanya. Sementara itu, calon mahasiswa memiliki kemudahan dalam memilih nama perguruan tinggi yang dapat memenuhi keinginannya.

Universitas Bunda Mulia sebagai salah satu lembaga pendidikan tinggi swasta di kawasan Jakarta Utara perlu melakukan penelitian tentang tingkat kepuasan para mahasiswanya. Dengan tingkat persaingan yang ketat, penelitian tentang loyalitas mahasiswa tersebut merupakan suatu tindakan yang sangat urgen. Upaya penelitian ini diharapkan akan memberikan masukan yang berarti bagi penyusunan strategi oleh para pengelola Universitas Bunda Mulia di masa yang akan datang.

\section{Perumusan Masalah}

Berdasarkan latar belakang permasalahan yang telah dikemukan di muka, maka secara umum perumusan masalah yang diajukan pada penelitian ini adalah sejauh mana dampak hubungan antara kepuasan pelanggan dan loyalitas pelanggan terhadap keinginan pembelian ulang secara keseluruhan.

\section{Tinjauan Pustaka}

Banyak definisi berkaitan dengan kepuasan pamakai (customer satisfaction) antara lain (Macintosh 2007) bahwa kepuasan merupakan evaluasi secara keseluruhan dari konsumen terhadap pengalam terhadap organisasi. Konsumen juga membuat penilaian dengan puas-tidak puasnya melalui kontak dengan pemasar. Semakin konsumen puas akan mendorong konsumen berkelakuan nyaman dan hal ini akan menghasilkan perilaku sukarela.

Dengan bahasa yang lebih sederhana (Kotler dan Keller 2006) menyebutkan kepuasan pelanggan sebagai: 
Tingkat perasaan seseorang setelah membandingkan kinerja (hasil) yang dirasakan dibandingkan dengan harapannya.

Kepuasan konsumen merupakan fungsi dari harapan pembeli atas produk atau jasa dengan kinerja yang dirasakan. Menurut (Kotler dan Keller 2006),

"Satisfaction is a person's feeling of pleasure or disappointment resulting from comparing a product perceived (or out me) in relations to his or her expectations".

Hal ini berarti bahwa : Kepuasan adalah perasaan senang atau kecewa seseorang yang disebabkan oleh kinerja suatu produk yang dirasakan dibandingkan dengan yang diharapkan.

Penelitian Andreassen (Solvang 2007) menyatakan bahwa konsumen yang loyal tidak selalu puas, tetapi konsumen yang puas cenderung loyal. Dengan demikian, pemasar harus membangun kepuas pelanggan karena konsumen yang puas akan cenderung loyal.

\section{Loyalitas Pelanggan}

Loyalitas pelanggan menunjukkan peningkatan hambatan berkembang dimaksudkan untuk membuat konsumen lebih sulit berpindah merek. Dalam hal ini, terdapat peningkatan frekuensi pembelian kembali maupun volume pembelian kembali yang meningkat. Loyalitas pelanggan ditunjukkan dengan suatu tingkat perilaku pembelian ulang yang tinggi dan memiliki sikap positif terhadap merek serta mungkin digunakan sikap positifnya dalam percakapan yang positif tentang merek yang bersangkutan.

(Bettencourt 1997) mendefinisikan loyalitas konsumen ketika konsumen percaya kalau suatu institusi peduli pada para pelanggan dan menghargai para pelanggan sebagai seorang konsumen. Sedangkan (Oliver dalam Taylor dkk 2004) menyatakan bahwa loyalitas merupakan komitmen yang mendalam untuk membeli kembali produk/jasa secara konsisten di masa yang akan datang sehingga menyebabkan pengulangan pembelian pada merek yang sama. Oliver juga menyarankan bahwa loyalitas konsumen yang tinggi merupakan fungsi dari superioritas produk yang dipersepsikan, keuletan pribadi, ikatan sosial dan efek sinerginya. 


\section{Pembelian Ulang}

Karena jasa merupakan scsuatu yang tidak dapat diraba (intangible) dan dicirikan tidak dapat dipisah-pisahkan, maka intcraksi antar pribadi yang terjadi selama penyampaian jasa seringkali merupakan efek terbesar pada persepsi kualitas jasa. Pembelian ulang merupakan keinginan untuk menggunakan kembali produk yang sama di masa yang akan datang.

Penelitian ini merupakan replikasi dari hasil penelitian (Solvang 2007). Solvang dalam tulisannya mencoba menyusun konseptual tentang hubungan antara jasa, kepuasan, rantai profil, loyalitas terhadap pembelian ulang. Penelitian ini mencoba melihat hubungan antara kepuasan, loyalitas terhadap hasrat pembelian ulang dalam konteks terbatas, yaitu sejauh mana kinerja yang diberikan pengelola Universitas Bunda Mulia kepada para pengguna jasa, dalam hal ini para mahasiswanya.

Berdasarkan hasil penelitian (Solvang 2007) tersebut, penelitian ini mencoba menganalisis dampak kinerja yang diberikan pengelola Universitas Bunda Mulia berdasarkan konstruk kepuasan pelanggan, konstruk loyalitas pelanggan, dan konstruk hasrat pembelian ulang.

Pembentukan model struktural ini merujuk pada model penelitian dari (Solvang 2007), dimana penelitian ini hendak menunjukkan adanya hubungan antara Kepuasan dan Loyalitas terhadap Hasrat Pembelian Ulang Konsumen di lembaga pendidikan tinggi Universitas Bunda Mulia (lihat Gambar 1.)

\section{Hipotesis}

Hipotesis penelitian ini adalah sebagai berikut :

$\mathbf{H}_{1}$ : Persepsi tentang kepuasan pelanggan berpengaruh secara signifikan pada persepsi tentang loyalitas pelanggan.

$\mathrm{H}_{2}$ : Persepsi tentang loyalitas pelanggan berpengaruh secara signifikan pada persepsi tentang keinginan pembelian ulang.

$\mathrm{H}_{3}$ : Persepsi tentang kepuasan pelanggan berpengaruh secara signifikan pada persepsi tentang keinginan pembelian ulang.

Berikut adalah gambar yang menunjukkan hubungan antara kepuasan pelanggan, loyalitas pelanggan, dan pembelian ulang: 


\section{Gambar 1}

Model hubungan antar Konstruk Penelitian ini

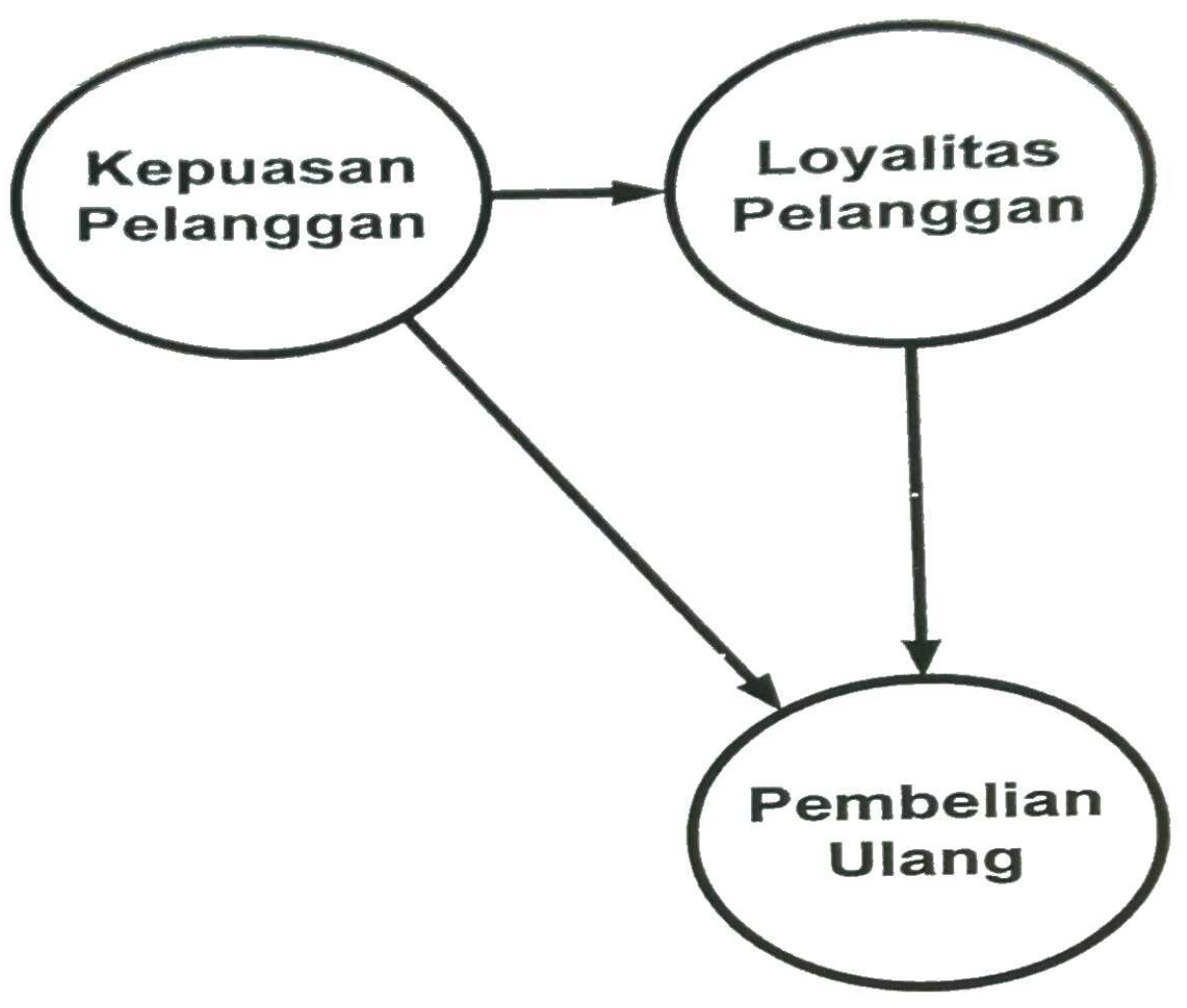

Sumber: (Solvang 2007)

\section{METODE PENELITIAN}

\section{Teknik Pengambilan Sampel}

Desain penelitian yang dipakai yaitu penelitian single cross-sectional. Jenis penelitian ini adalah eksplanatoris, maksudnya untuk memperoleh penjelasan mengenai sejauh mana dampak hubungan antara kepuasan pelanggan dan loyalitas pelanggan terhadap keinginan pembelian ulang secara keseluruhan.

Sampel penelitian ini adalah para mahasiswa Universitas Bunda Mulia (UBM). Mereka mengisi angket kuesioner guna menilai kepuasan mereka sebagai pengguna jasa pendidikan di Universitas Bunda Mulia. Mereka tersebut juga mengevaluasi diri mereka sendiri tentang dampak hubungan antara kepuasan pelanggan dan loyalitas pelanggan terhadap keinginan pembelian ulang secara 
keseluruhan. Pengambilan sampel dilakukan di Universitas Bunda Mulia (UBM) dan telah dilaksanakan pada pertengahan bulan Juni 2008.

Teknik pengambilan sampel yang akan digunakan dalam penelitian ini adalah purposive random sampling. Pada metode ini, setiap responden yang memberikan tanggapan pada setiap butir pernyataan yang berkaitan dengan Kepuasan Pelanggan, Loyalitas Pelanggan dan hubungannya dengan hasrat Pembelian Ulang para responden (mahasiswa Universitas Bunda Mulia.

\section{Variabel dan Pengukurannya}

Skala pengukuran yang dipakai dalam penelitian adalah skala nominal dan skala Likert. Setiap pernyataan tersebut dapat diukur dengan memberi 7 alternatif tanggapan, yaitu : Sangat Tidak Setuju (skor 1), Tidak Setuju (skor 2), , Agak Tidak Setuju (skor 3), Biasa-biasa saja (skor 4), Agak Setuju (skor 5), Setuju (skor 6), dan Sangat Setuju (skor 7).

\section{Metode Pengumpulan Data}

Metode pengumpulan data yang dipakai dalam penelitian ini adalah metode pengumpulan data primer. Data primer merupakan data yang diperoleh secara langsung dari sumbernya dengan tidak melalui perantara. Sumber data tersebut adalah para mahasiswa Universitas Bunda Mulia (UBM) yang memberikan pendapat mereka tentang Kepuasan Pelanggan, Loyalitas Pelanggan dan hasrat Pembelian Ulang mereka. Media yang digunakan peneliti untuk mengumpulkan data primer tersebut adalah berupa kuesioner.

\section{Teknik Analisis Data}

Pengolahan data menggunakan metode statistik Structural Equation Modeling (SEM). Setiap variabel penelitian diuji kesesuaiannya terhadap konsep (construct) yang dikembangkan melalui Unidimensionality.

Setelah variabel-variabel (indikator) penelitian yang tidak relevan atau loading factor-nya rendah dikeluarkan dari model penelitian, langkah selanjutnya melakukan uji kesesuaian (goodness of fit) terhadap Structural Model. 


\section{ANALISIS DAN PEMBAHASAN}

\section{Profil Responden}

Responden penelitian ini adalah para mahasiswa di Universitas Bunda Mulia yang akan ditinjau meliputi: Angkatan Kuliah, Jurusan, Alat Transportasi, dan Jenis Kelamin. Penyebaran kuesioner dilakukan pada tanggal 18, 19, dan 20 Juni 2008. Penyebaran kuesioner tersebut dilakukan dengan bantuan 10 orang mahasiswa jurusan Manajemen angkatan 2006/2007 yang mengikuti matakuliah Manajemen Pemasaran Lanjutan. Ada 232 responden dalam penelitian ini yang dapat dikumpulkan dengan deskripsi sebagai berikut:

a. Proporsi Angkatan Kuliah

Ditinjau dari sudut pandang Angkatan Kuliah, maka sebagian besar responden dalam penelitian ini adalah responden angkatan 2007/2008 (sebanyak 74,6\%) sedangkan responden paling sedikit terjaring dalam penelitian adalah responden angkatan 2004/2005 dan angkatan 2006/2007, masing-masing sebanyak 1,7\%.

b. Proporsi Jurusan

Ditinjau dari Jurusan responden yang kuliah, maka sebagian besar responden dalam penelitian ini adalah responden dari jurusan sistem Informasi (sebanyak 19,0\%) sedangkan responden dari jurusan Teknik Industri merupakan responden yang paling sedikit terjaring hanya $1,7 \%$.

c. Proporsi Alat Transportasi

Ditinjau dari proporsi Alat Transportasi, maka sebagian besar responden dalam penelitian ini adalah pengguna sepeda motor (sebesar 43,1 \%), disusul pengguna kendaraan umum (22,0 \%). Pengguna paling sedikit adalah kendaraan yang disediakan oleh UBM berupa bus (hanya 1,3\%)

d. Proporsi Jenis Kelamin

berdasarkan jenis kelamin responden, maka responden yang paling banyak terjaring mengisi kuesioner penelitian adalah responden berjenis kelamin laki-laki yaitu 122 orang (52,6\%) sedangkan responden perempuan sebanyak 110 orang responden $(47,4 \%)$. 


\section{Analisis Inferensial}

Sebelum pengujian hipotesis penelitian, terlebih dahulu akan diuji validitas dan reliabilitas alat ukur penelitian ini yaitu butir-butir pernyataan di kuesioner tersebut. Selanjutnya pembahasan besarnya kontribusi variabel Kepuasan Pelanggan terhadap variabel Loyalitas Pelanggan dari para mahasiswa UBM, besarnya kontribusi variabel Loyalitas Pelanggan terhadap variabel hasrat Pembelian Ulang.

\section{Uji Validitas dan Uji Reliabilitas}

Uji validitas dan uji reliabilitas dalam penelitian ini menggunakan program statistik Lisrel. Cara menguji validitas dan reliabilitas butir-butir pernyataan yaitu; membuang nilai T-values yang tidak signifikan.

Kriteria suatu butir pernyataan tidak valid dan tidak reliabel adalah angka output-nya berada dibawah taraf signifikansi. Nilai signifikansi pada taraf kesalahan $($ alpha $=\alpha) 5 \%=1.96$.

Berikut adalah gambar yang menunujukkan hubungan antara kepuasan pelanggan, Loyalitas pelanggan, dan pembelian ulang: 


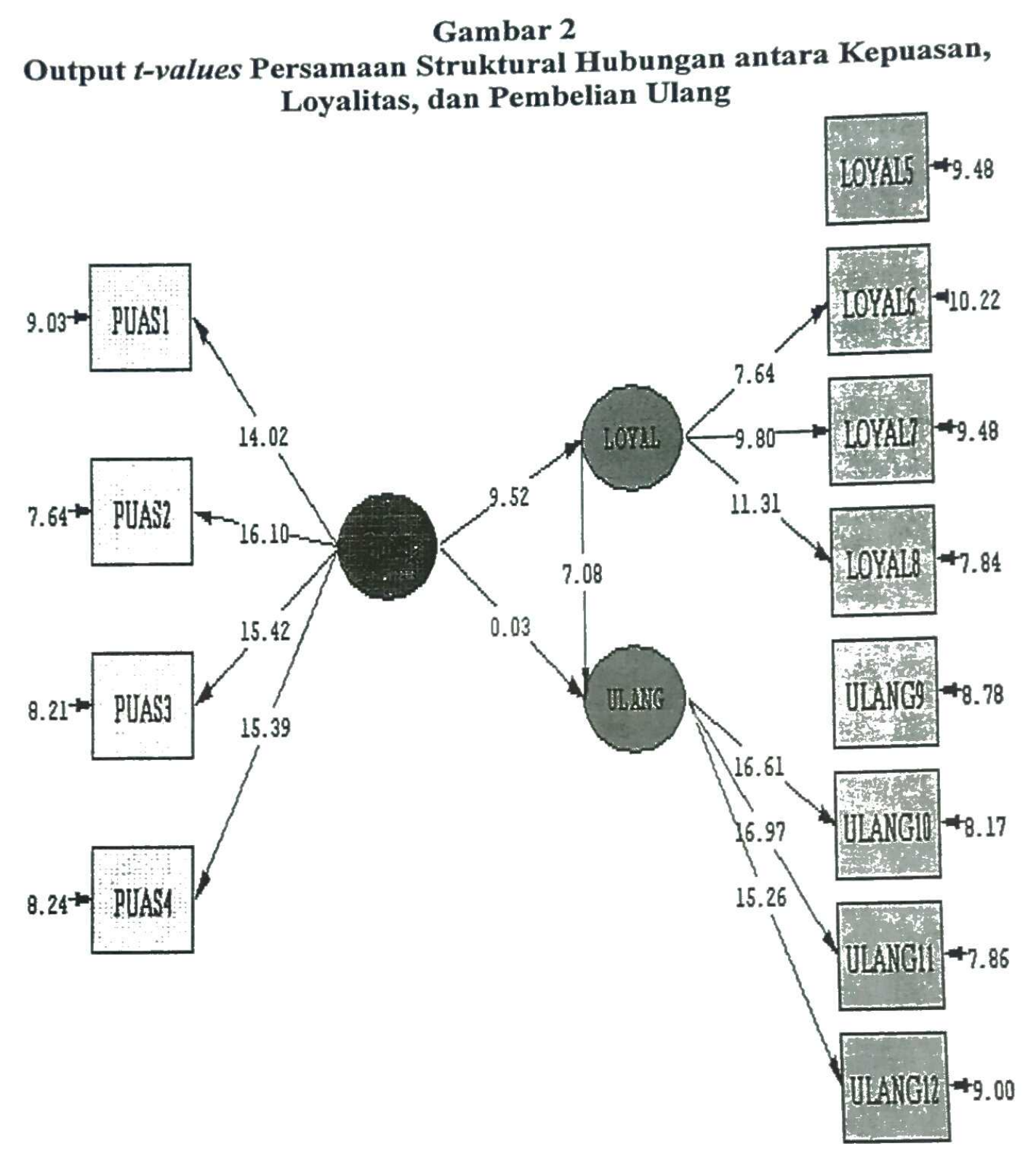

Chi-9quare=99.50, df $=51$, P-value $=0.00006$, RMSEA $=0.064$

\section{Sumber : Data Diolah}

Berdasarkan Gambar 2 tersebut, terlihat bahwa semua nilai butir-butir pernyataan kuesioner memenuhi taraf signifikansi nilai T-values $(< \pm 1,96)$.

Namun pengaruh konstruk kepuasan pelanggan terhadap hasrat pembelian ulang memiliki taraf signifikansi $\mathrm{T}$-values $(< \pm 1,96)$. Ini berarti tidak signifikan 
karena memiliki nilai $T$-values sebesar $0,03 \quad(<1,96$ pada taraf signifikansi alpha $=\alpha=5 \%)$.

\section{Uji Hipotesis}

Setelah ditemukan butir-butir yang valid dan reliabel, langkah berikutnya adalah melakukan analisis hipotesis.

Hipotesis penelitian ini adalah sebagai berikut:

$\mathrm{H}_{1}$ : Persepsi tentang kepuasan pelanggan berpengaruh secara signifikan pada persepsi tentang loyalitas pelanggan.

$\mathrm{H}_{2}$ : Persepsi tentang loyalitas pelanggan berpengaruh secara signifikan pada persepsi tentang keinginan pembelian ulang.

$\mathrm{H}_{3}$ : Persepsi tentang kepuasan pelanggan berpengaruh secara signifikan pada persepsi tentang keinginan pembelian ulang.

Kriteria signifikansi hubungan di antara dua variabel penelitian dengan pendekatan program SEM adalah hipotesis nol ditolak bila nilai signifikansi pada taraf alpha $(\alpha) 5 \%>1,96$.

Berdasarkan output uji T-values antara variabel Kepuasan Pelanggan dengan variabel Loyalitas Pelanggan sebagaimana terlihat pada Gambar 2, diperoleh hasil t-hitung sebesar 9,52. Karena nilai $t_{\text {hitung }}(=9,52)>t_{-\alpha}(=1,96)$, maka dapat disimpulkan bahwa hipotesis ditolak. Dengan demikian dapat dikatakan bahwa terdapat hubungan yang signifikan persepsi tentang kepuasan pelanggan terhadap persepsi tentang loyalitas para pelanggan (mahasiswa UBM).

Berdasarkan output uji T-values antara variabel Loyalitas Pelanggan terhadap variabel hasrat Pembelian Ulang sebagaimana terlihat pada Gambar 2, diperoleh hasil t-hitung sebesar 7,08. Karena nilai $t_{\text {-hitung }}(=7,08)>t_{\alpha}(=1,96)$, maka dapat disimpulkan bahwa hipotesis ditolak. Dengan demikian dapat dikatakan bahwa terdapat hubungan yang signifikan persepsi tentang loyalitas pelanggan terhadap persepsi tentang hasrat pembelian ulang para pelanggan (mahasiswa UBM).

Berdasarkan output uji T-values antara variabel Kepuasan Pelanggan dengan variabel hasrat pembelian ulang sebagaimana terlihat pada Gambar 2, diperoleh hasil t-hitung sebesar 0,03 . Karena nilai $\mathrm{t}_{\text {-hitung }}(=0,03)<\mathrm{t}_{-\alpha}(=1,96)$, 
maka dapat disimpulkan bahwa hipotesis diterima. Dengan demikian dapat dikatakan bahwa tidak terdapat hubungan yang signifikan persepsi tentang kepuasan pelanggan terhadap persepsi tentang hasrat pembelian ulang (para mahasiswa UBM).

\section{Kontribusi Konstruk}

Berdasarkan tabel 1, terlihat bahwa besarnya kontribusi Kepuasan Pelanggan terhadap Loyalitas Pelanggan sebesar $62 \%\left(\mathrm{R}^{2}=0.62\right)$ sedangkan $38 \%$ $(100 \%-62 \%)$ disebabkan karena faktor-faktor lain.

Hal ini berarti kontribusi Kepuasan Pelanggan terhadap Loyalitas Pelanggan relatif sedang.

Tabel 1

Kontribusi Loyalitas Pelanggan dan Hasrat Pembelian Ulang

LOYAL $=0.79 *$ PUAS, Errorvar. $=0.38$, Rý $=0.62$

(0.083) (0.081)

9.52 4.73

ULANG $=0.90 *$ LOYAL $+0.0035 *$ PUAS, Errorvar. $=0.18$, Rý $=0.82$ $(0.047)$

$\begin{array}{lll}7.08 & 0.035 & 3.85\end{array}$

Sumber : Data diolah

Berdasarkan tabel 1 pula, terlihat bahwa besarnya kontribusi Loyalitas Pelanggan terhadap Hasrat Pembelian Ulang sebesar $82 \%\left(R^{2}=0.82\right)$.

Sedangkan $18 \%(100 \%-82 \%)$ disebabkan karena faktor-faktor lain. Hal ini berarti kontribusi Loyalitas Pelanggan terhadap Hasrat Pembelian Ulang relatif tinggi. 


\section{KESIMPUIAN DAN SARAN}

Berdasarkan hasil penelitian tersebut dapat diambil kesimpulan bahwa penelitian ini tidak sesuai dengan penelitian awal yang dilakukan olch (Solvang 2007).

Dalam penelitian Solvang, konsumen yang puas akan secara langsung melakukan pembelian ulang dalam bentuk menyarankan saudaranya, adik-adik angkatan di SMU agar memilih kuliah di Universitas Bunda Mulia.

Penclitian ini konstruk Puas tidak sccara langsung mempengaruhi konstruk Pembelian Ulang. Fakta ini mengakibatkan pengelola Universitas Bunda Mulia tetap meningkatkan kepuasan mahasiswa guna meningkatkan loyalitas mahasiswa.

Ketika mahasiswa loyal, ketika itu mahasiswa cenderung menyarankan saudaranya dan adik-adik angkatan di SMU agar bersedia kuliah di Universitas Bunda Mulia mengikuti jejaknya.

Adapun saran yang dapat diberikan adalah sebagai berikut:

1. Manajemen perlu meningkatkan kepuasan mahasiswa, namun pimpinan Universitas Bunda Mulia perlu menyadari bahwa mahasiswa yang puas belum tentu menyarankan teman, saudaranya, orang-orang yang dikenalnya untuk kuliah di Universitas Bunda Mulia.

2. Karena konsumen yang loyal cenderung menyarankan orang lain mengalami pengalaman positif yang sama dengan dirinya, maka pimpinan perlu meningkatkan loyalitas mahasiswa yang sudah ada.

\section{DAFTAR PUSTAKA}

Bettencourt, L.A., 1997, 'Customer Voluntary Performance: Customers As Partners In Service Delivery', Journal of Retailing, Vol 73, No 3.

Cronin, J.J. dan Taylor, S.A., 1994, 'SERVPERF versus SERVQUAL', Journal of Marketing, Vol. 58, no 1.

Ghozali, Imam dan Fuad., 2005, Structural Equation Modeling:teori, konsep, \& aplikasi dengan program LISREL 8.54, Badan Penerbit Universitas Diponegoro, Semarang 
Hair, Joseph F., et.al., 1998, Multivariate Data Analysis, Fifth Edition, Upper Saddle River:Prentice-Hall, Inc., New York.

Kotler, P., dan Kevin L. Keller., 2006, Marketing Management, Pearson Education, Inc.

Macintosh, G., 2007, 'Customer Orientation, Relationship Quality, Relational Benefits to the Firm', Journal of Services Marketing, vol. 21 No. 3.

Maholtra, Naresh K., 1999, Marketing Research: an Applied Orientation, Third Edition. Upper Saddle River,Prentice-Hall, Inc., New York

Solvang, B.K., 2007, 'Satisfaction, Loyalty, and Repurchase', Journal of Consumer Satisfaction, Dissatiftaction and Coplaining Behavior, Vol. 20.

Taylor, S.A. et al., 2004, 'The Importance of Brand Equity to Customer Loyalty', The Journal of Product and Brand Management, vol. 13, No. 4/5. 